\title{
A nomogram predicting pulmonary metastasis of hepatocellular carcinoma following partial hepatectomy
}

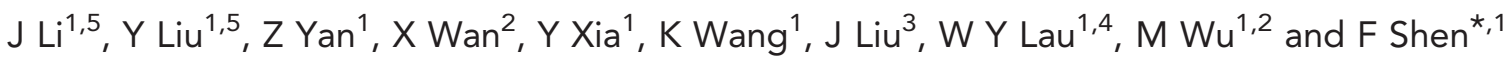

${ }^{1}$ Department of Hepatic Surgery, Eastern Hepatobiliary Surgery Hospital, Second Military Medical University, Shanghai 200438, China; ${ }^{2}$ Department of Clinical Database, Eastern Hepatobiliary Surgery Hospital, Second Military Medical University, Shanghai 200438, China; ${ }^{3}$ Department of Hepatobiliary Surgery, The First Affiliated Hospital, Fujian Medical University, Fuzhou 350005, China and ${ }^{4}$ Faculty of Medicine, The Chinese University of Hong Kong, Hong Kong, China

Background: Pulmonary metastasis (PM) following curative hepatectomy for hepatocellular carcinoma (HCC) is indicative of a poor prognosis. This study aimed to develop a nomogram to identify patients at high risks of PM.

Methods: A primary cohort of patients who underwent curative hepatectomy for HCC at the Eastern Hepatobiliary Surgery Hospital from 2002 to 2010 was prospectively studied. A nomogram predicting PM was constructed based on independent risk factors of PM. The predictive performance was evaluated by the concordance index (c-index), calibration curve and decision curve analysis (DCA). During the study period, a validation cohort was included at the First Affiliated Hospital of Fujian Medical University.

Results: Postoperative PMs were detected in 106 out of 620 and 45 out of 218 patients, respectively, in two cohorts. Factors included in the nomogram were microvascular invasion, serum alpha-fetoprotein, tumour size, tumour number, encapsulation and intratumoral CD34 staining. The nomogram had a c-index of 0.75 and 0.82 for the two cohorts for predicting PM, respectively. The calibration curves fitted well. In the two cohorts, the DCA demonstrated positive net benefits by the nomogram, within the threshold probabilities of $\mathrm{PM}>10 \%$.

Conclusion: The nomogram was accurate in predicting PM following curative hepatectomy for HCC.

Hepatocellular carcinoma (HCC) is the fifth common malignancy and a major cause of cancer-related mortality (Ferlay et al, 2010). Partial hepatectomy and transplantation still remain the major curative therapeutic options available to patients with HCC. However, following partial hepatectomy there is a significant chance of recurrence (Poon et al, 2000). Although intrahepatic recurrence is most common after operation, extrahepatic metastases (EHMs) still account for 14.0-25.5\% of all recurrences. Pulmonary metastases (PMs) represent nearly 50\% of all EHM (Hong et al, 2003; Yang et al, 2007; Li et al, 2012).

For most cancers, PM signifies systemic disease that is not curable with surgery. However, in the past two decades, data from some institutions suggested that pneumonectomy for PM of HCC could achieve a long-term survival, although it needs to be offered in well-selected patients with the lung as the only extrahepatic metastatic site and single PM lesion, and with a long disease-free interval (Chua and Morris, 2012). In addition, two recent studies with more than $22 \%$ of patients with PM showed sorafenib to prolong overall survival in patients with advanced HCC (Llovet et al, 2008; Cheng et al, 2009). In animals using orthotopic models, sorafenib also suppressed postresectional intrahepatic and distant metastasis of HCC, making it a potential choice in the prevention of postoperative PM (Feng et al, 2011), although the results of a phase III clinical trial that assesses the efficacy of sorafenib as an

${ }^{*}$ Correspondence: Professor F Shen; E-mail: shenfengehbh@sina.com
${ }^{5}$ These authors contributed equally to this work.

Received 9 September 2013; revised 29 November 2013; accepted 2 January 2014; published online 30 January 2014 
adjuvant therapy for HCC following partial hepatectomy are not yet available. Thus, the ability to identify HCC patients who are at high risks of developing postoperative PM facilitates not only early detection of PM lesions that are suitable for lung resection, but also identification of patients who might benefit from adjuvant therapies.

PM of HCC is hard to predict on clinical ground. A nomogram is a statistical tool that provides the overall probability of a specific outcome for an individual patient (Kattan and Scardino, 2007). In this study we constructed a nomogram from a primary cohort of patients to predict the likelihood of PM in patients with HCC after partial hepatectomy, and validated the nomogram with a validation cohort of patients.

\section{MATERIALS AND METHODS}

Patients. Consecutive patients with pathologically proven HCC after curative partial hepatectomy carried out between July 2002 and April 2010 at the fourth Department of Hepatic Surgery of the Eastern Hepatobiliary Surgery Hospital $(\mathrm{EHBH})$ were enrolled into this study. The data of these patients were collected prospectively and analysed retrospectively. The definition of curative resection has been described in our previous study (Wang et al, 2010).

Data from another independent cohort of consecutive patients who underwent curative partial hepatectomy for HCC at the Department of Hepatobiliary Surgery, the First Affiliated Hospital of Fujian Medical University, during the same study period were collected retrospectively.

The clinical staging was based on the Barcelona Clinic Liver Cancer system and the seventh edition of the TNM/AJCC classification (Edge et al, 2009; European Association for the Study of the Liver, European Organisation for Research and Treatment of Cancer, 2012). Tumour differentiation was based on the Edmondson-Steiner classification. Paraffin-embedded tissue blocks were obtained after partial hepatectomy. Immunohistochemical staining of CD34, CK18, CK19 and HepPra-1 in tumour tissues was routinely performed in the pathological analysis. The status of these markers was considered positive if $\geqslant 50 \%$ of cells stained positively.

The study was approved by the Institutional Ethics Committee from the two hospitals and it was censored on 19 October 2012. Informed consent was obtained from all the patients before surgery for using their data in research.

Hepatectomy and follow-up. Partial hepatectomy was carried out based on Couinaud's segments/sectors/hemilivers, tumour diameter, location, presence/absence of cirrhosis and estimated volume of future liver remnant. An anatomical hepatectomy was the preferred method if the tumour was within a segment/sector/ hemiliver provided that the liver remnant could well compensate for the liver function. A non-anatomical resection was used for tumours situated at the junction of several segments, or for peripherally located tumours, or for patients who could not tolerate an anatomical resection.

Patients were followed up once every $2-3$ months during the first 2 years after surgery, and once every 3-6 months thereafter. In each follow-up visit, the routine examination was carried out, including a detailed clinical history and physical examination, blood tests for hepatitis B and C immunology, hepatitis B virus (HBV)-DNA load, liver function and serum alpha-fetoprotein (AFP), chest X-ray and abdominal ultrasound (US). Computerised tomography (CT) of the chest, and contrast-enhanced CT and/or magnetic resonance imaging of the abdomen were performed every 6 months or earlier when tumour recurrence/metastasis was suspected. Hepatic angiography or $18 \mathrm{~F}$-fluorodeoxyglucose positron emission tomography was only carried out for patients whose recurrences were not well identified by the above methods. For the patient who survived for a disease-free interval $\geqslant 5$ years, the follow-up was performed less frequently as once every 6-12 months, with the examination of serum tests, abdominal US and chest X-ray.

The diagnosis of PM was mainly based clinically as previously reported (Bhattacharjya et al, 2006; Baek et al, 2012; Kong et al, 2012). The diagnostic criteria were: (a) new and growing lesions, especially multiple, round nodules in the periphery of lungs on dynamic chest CT scan; (b) elevation of serum AFP levels, especially in patients with initially raised serum AFP, which decreased after liver resection. Cytological examination of sputum, bronchofibrescopic brushing or bronchial perfusate was used in differentiating other lung lesions. Patients with PM diagnosed before or simultaneously with intrahepatic recurrence and/or extrapulmonary metastasis were included into this study. Patients with PM diagnosed later than any other recurrences were not analysed in this study because these cases could be metastases from these recurrent lesions instead of from the primary tumour, which had been resected.

Statistical analysis. The clinical end points were the time to PM and overall survival. The time to PM was calculated from the date of surgery to the date when PM was diagnosed or to the last followup visit. The overall survival was the interval between the date of liver resection to the date of death or the last follow-up. Categorical variables were compared using the $\chi^{2}$-test or Fisher's exact test. Continuous variables were compared using the $t$-test or MannWhitney $U$-test. A competing risk survival analysis was conducted to identify risk factors of PM in the primary cohort, and treating deaths, intrahepatic and other EHMs before PM as competing events.

A final model selection for nomogram was performed by a backward step-down selection process using a threshold $P$-value of $<0.05$. The performance of the nomogram was measured by concordance index ( $c$-index) and assessed by calibration. Aiming at more stability, a 10-fold cross-validation was done and repeated 100 times, and the average $c$-index was calculated. In calibration, the predicted probability of PM generated using 10-fold cross validation was compared with the observed cumulative incidence estimates of PM probability. The validation cohort and all the patients within the Milan criteria (Mazzaferro et al, 1996) were analysed using the method reported before (Wang et al, 2013).

The decision curve analysis (DCA) was used to evaluate the nomogram for the prediction of PM. This method incorporates the clinical consequences of the nomogram by applying a different weight to the true- and false-positive results. This weighting was varied to reflect the difference in patient preferences or differences in opinion on the risks of a procedure. These preferences were expressed in terms of a threshold probability for action. DCA provides a net benefit, which was calculated using the formula: net benefit $=$ true-positives $/ n-$ false-positives $/ n \times(\mathrm{pt} /(1-\mathrm{pt}))$. In this formula, pt is the threshold probability of PM. Then, the net reduction in interventions per 100 patients could be calculated accordingly. The optimal model is one with a high net benefit as calculated within the favourable probability. This technique and the interpretation of the final result are available in a step-by-step tutorial online (Vickers and Elkin, 2006; Steyerberg and Vickers, 2008).

The statistical analysis was carried out using STATA 12 for Windows (Stata Press, College Station, TX, USA) and R 2.13.2 (http://www.r-project.org/) with library rms, cmprsk and QHScrnomo (Cahlon et al, 2012).

\section{RESULTS}

Of the 681 patients who received partial hepatectomy at the EHBH during the study period, we excluded patients with a history of 


\begin{tabular}{|c|c|c|c|c|}
\hline & Primary coho & & Validation col & \\
\hline Variables & No. of patients & $\%$ & No. of patients & $\%$ \\
\hline No. of patients & 620 & 100 & 218 & 100 \\
\hline \multicolumn{5}{|l|}{ Age, years } \\
\hline $\begin{array}{l}\text { Median } \\
\text { Range }\end{array}$ & $\begin{array}{r}51.4 \\
17-78\end{array}$ & & $\begin{array}{r}53.0 \\
16-77\end{array}$ & \\
\hline \multicolumn{5}{|l|}{ Sex } \\
\hline \begin{tabular}{|l} 
Male \\
Female
\end{tabular} & $\begin{array}{r}557 \\
63\end{array}$ & $\begin{array}{l}89.8 \\
10.2\end{array}$ & $\begin{array}{r}192 \\
26\end{array}$ & $\begin{array}{l}88.1 \\
11.9\end{array}$ \\
\hline \multicolumn{5}{|l|}{ HBsAg } \\
\hline \begin{tabular}{|l|} 
Negative \\
Positive
\end{tabular} & $\begin{array}{l}110 \\
510\end{array}$ & $\begin{array}{l}17.7 \\
82.3\end{array}$ & $\begin{array}{r}48 \\
170\end{array}$ & $\begin{array}{l}22.0 \\
78.0\end{array}$ \\
\hline \multicolumn{5}{|l|}{ HCV-Ab } \\
\hline \begin{tabular}{|l|} 
Negative \\
Positive
\end{tabular} & $\begin{array}{r}601 \\
19\end{array}$ & $\begin{array}{r}96.9 \\
3.1\end{array}$ & $\begin{array}{r}210 \\
8\end{array}$ & $\begin{array}{r}96.3 \\
3.7\end{array}$ \\
\hline \multicolumn{5}{|l|}{ PT, second } \\
\hline \begin{tabular}{|l} 
Median \\
Range
\end{tabular} & $\begin{array}{r}11.9 \\
8-19.4\end{array}$ & & $\begin{array}{c}12 \\
9.9-12.4\end{array}$ & \\
\hline \multicolumn{5}{|l|}{ ALB, $\mathrm{gl}^{-1}$} \\
\hline \begin{tabular}{|l} 
Median \\
Range
\end{tabular} & $\begin{array}{r}41.5 \\
28-80\end{array}$ & & $\begin{array}{c}42 \\
30-50.9\end{array}$ & \\
\hline \multicolumn{5}{|l|}{ TBIL, $\mu \mathrm{moll}^{-1}$} \\
\hline $\begin{array}{l}\text { Median } \\
\text { Range }\end{array}$ & $\begin{array}{r}14.7 \\
4.9-80\end{array}$ & & $\begin{array}{c}15 \\
6-40\end{array}$ & \\
\hline \multicolumn{5}{|l|}{$A L T, U^{-1}$} \\
\hline $\begin{array}{l}\text { Median } \\
\text { Range }\end{array}$ & $\begin{array}{c}40.9 \\
5.8-819.8\end{array}$ & & $\begin{array}{c}39.0 \\
10-1689\end{array}$ & \\
\hline \multicolumn{5}{|l|}{ AFP, $\mu \mathrm{g} \mathrm{ml}^{-1}$} \\
\hline $\begin{array}{l}\text { Median } \\
\text { Range }\end{array}$ & $\begin{array}{c}114.2 \\
1-120101\end{array}$ & & $\begin{array}{c}78.5 \\
1-60500\end{array}$ & \\
\hline \multicolumn{5}{|l|}{ Hepatectomy } \\
\hline $\begin{array}{l}\text { Anatomical } \\
\text { Non-anatomical }\end{array}$ & $\begin{array}{l}358 \\
620\end{array}$ & $\begin{array}{l}57.7 \\
42.3\end{array}$ & $\begin{array}{r}123 \\
95\end{array}$ & $\begin{array}{l}56.4 \\
43.6\end{array}$ \\
\hline \multicolumn{5}{|l|}{ Cirrhosis } \\
\hline $\begin{array}{l}\text { No } \\
\text { Yes }\end{array}$ & $\begin{array}{l}409 \\
211\end{array}$ & $\begin{array}{l}66.0 \\
34.0\end{array}$ & $\begin{array}{r}159 \\
59\end{array}$ & $\begin{array}{l}72.9 \\
27.1\end{array}$ \\
\hline \multicolumn{5}{|c|}{ Tumour size, $\mathrm{cm}$} \\
\hline $\begin{array}{l}\text { Median } \\
\text { Range }\end{array}$ & $\begin{array}{c}5 \\
1-23.2\end{array}$ & & $\begin{array}{r}5.1 \\
1-19\end{array}$ & \\
\hline \multicolumn{5}{|c|}{ No. of tumours } \\
\hline $\begin{array}{l}\text { Single } \\
\text { Multiple }\end{array}$ & $\begin{array}{r}551 \\
69\end{array}$ & $\begin{array}{l}88.9 \\
11.1\end{array}$ & $\begin{array}{r}170 \\
48\end{array}$ & $\begin{array}{l}78.2 \\
12.8\end{array}$ \\
\hline \multicolumn{5}{|l|}{ Capsule } \\
\hline $\begin{array}{l}\text { Incomplete } \\
\text { Complete }\end{array}$ & $\begin{array}{l}382 \\
238\end{array}$ & $\begin{array}{l}61.6 \\
38.4\end{array}$ & $\begin{array}{r}126 \\
92\end{array}$ & $\begin{array}{l}57.8 \\
42.2\end{array}$ \\
\hline
\end{tabular}

Table 1. (Continued)

\section{Primary cohort $\quad$ Validation cohort}

\begin{tabular}{l|l|l|l|l} 
Variables & No. of patients & $\%$ & No. of patients & $\%$
\end{tabular}

Edmondson-Steiner classification

\begin{tabular}{|l|r|r|r|l|}
\hline I-II & 133 & 21.5 & 43 & 19.7 \\
III-IV & 487 & 78.5 & 175 & 80.3 \\
\hline
\end{tabular}

MVI

\begin{tabular}{|l|r|r|r|l|}
\hline Absence & 449 & 72.4 & 150 & 68.8 \\
Presence & 171 & 27.6 & 68 & 31.2 \\
\hline
\end{tabular}

Surgical margin, $\mathrm{cm}$

\begin{tabular}{|l|c|c|c}
\hline Median & 0.9 & 0.8 \\
Range & $0.1-3.5$ & & $0.1-2.0$
\end{tabular}

\section{Blood transfusion}

\begin{tabular}{|l|r|r|r|l|}
\hline No & 510 & 82.3 & 187 & 85.8 \\
Yes & 110 & 17.7 & 31 & 14. \\
\hline
\end{tabular}

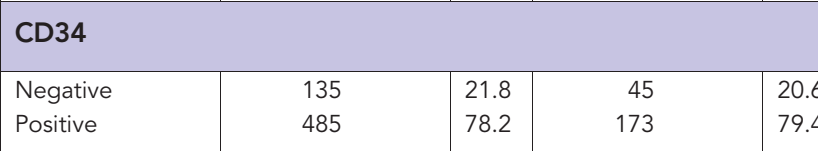

\begin{tabular}{|l|r|r|r|l|}
\hline CK18 \\
\hline Negative & 202 & 32.6 & 55 & 25.2 \\
Positive & 418 & 67.4 & 163 & 74.8 \\
\hline
\end{tabular}

\begin{tabular}{|l|r|r|r|r|}
\hline CK19 \\
\hline Negative & 557 & 89.8 & 198 & 90.8 \\
Positive & 63 & 10.2 & 20 & 9.2 \\
\hline
\end{tabular}

HepPar-1

\begin{tabular}{|l|r|r|r|l|}
\hline Negative & 145 & 23.4 & 32 & 14.7 \\
Positive & 475 & 76.6 & 186 & 85.3 \\
\hline
\end{tabular}

\section{Milan criteria}

\begin{tabular}{|l|l|l|l|l|}
\hline Within & 318 & 51.3 & 110 & 50.5 \\
Beyond & 302 & 48.7 & 108 & 49.5 \\
\hline
\end{tabular}

Abbreviations: $A F P=$ alpha-fetoprotein; $A L B=$ albumin; $A L T=$ alanine aminotransferase; CD34 = cluster of differentiation $34 ; \quad C K 18$ and $19=$ Cytokeratin 18 and 19; $\mathrm{HBsAg}=$ hepatitis B surface antigen; $\mathrm{HCV}=$ hepatitis $\mathrm{C}$ virus; HepPar-1=hepatocyte paraffin 1; $\mathrm{MVI}=$ microvascular invasion; $\mathrm{PT}=$ prothrombin time; $\mathrm{TBIL}=$ total bilirubin.

preoperative anti-cancer therapy $(n=23)$, uncertain preoperative pulmonary lesions $(n=4)$, other malignancies $(n=6 ; 4$ diagnosed before and 2 after hepatectomy), tumours with major vascular invasion or $\operatorname{EHM}(n=13)$, incomplete data $(n=12)$ and in-hospital mortality $(n=3)$. Finally, 620 patients formed the primary cohort.

Of the 249 patients who received partial hepatectomy at the First Affiliated Hospital of Fujian Medical University during the study period, we excluded patients who had a history of preoperative anti-cancer therapy $(n=10)$, other malignancies $(n=3)$, tumours with major vascular invasion and EHM $(n=7)$, incomplete data $(n=9)$ and in-hospital mortality $(n=2)$. Finally, 218 patients comprised the validation cohort.

Clinicopathological characteristics. The clinicopathological characteristics of the patients are shown in Table 1. Most patients were men $(89.4 \%)$, were positive for HBV surface antigen $(81.2 \%)$ 
Table 2. Independent risk factors predicting PM in the primary cohort

Univariate analysis

Multivariate analysis

\begin{tabular}{|c|c|c|c|c|c|c|}
\hline Variables & HR & $95 \% \mathrm{Cl}$ & $\boldsymbol{P}$-value & HR & $95 \% \mathrm{Cl}$ & $\boldsymbol{P}$-value \\
\hline Age, years & 0.97 & $0.95-0.99$ & 0.495 & & & NA \\
\hline Sex: male vs female & 1.40 & $0.68-2.90$ & 0.365 & & & NA \\
\hline HBsAg: positive vs negative & 1.55 & $0.89-2.70$ & 0.119 & & & NA \\
\hline PT, second & 1.07 & $0.94-1.21$ & 0.305 & & & NA \\
\hline$A L B,\left.g\right|^{-1}$ & 1.01 & $0.97-1.05$ & 0.588 & & & NA \\
\hline $\mathrm{TBIL}, \mu \mathrm{moll} \mathrm{I}^{-1}$ & 1.00 & $0.98-1.02$ & 0.921 & & & NA \\
\hline $\mathrm{ALT}, \mathrm{UI}^{-1}$ & 1.00 & $1.00-1.00$ & 0.509 & & & NA \\
\hline $\log (A F P)$ & 1.37 & $1.14-1.65$ & 0.001 & 1.34 & $1.10-1.62$ & 0.004 \\
\hline $\begin{array}{l}\text { Hepatectomy: anatomical vs } \\
\text { non-anatomical }\end{array}$ & 0.98 & $0.66-1.44$ & 0.903 & & & \\
\hline Cirrhosis: yes vs no & 1.02 & $0.69-1.52$ & 0.908 & & & NA \\
\hline Tumour size, $\mathrm{cm}$ & 1.10 & $1.06-1.14$ & $<0.001$ & 1.08 & $1.03-1.13$ & 0.001 \\
\hline No. of tumours: multiple vs single & 2.07 & $1.30-3.27$ & 0.002 & 1.72 & $1.02-2.88$ & 0.041 \\
\hline Capsule: incomplete vs complete & 1.64 & $1.08-2.50$ & 0.021 & 2.84 & $1.70-4.76$ & $<0.001$ \\
\hline Differentiation: III-IV vs I-II & 1.55 & $0.92-2.62$ & 0.103 & & & NA \\
\hline MVI: presence vs absence & 4.08 & $2.78-5.99$ & $<0.001$ & 3.73 & $2.44-5.70$ & $<0.001$ \\
\hline Surgical margin, $\mathrm{cm}$ & 0.69 & $0.51-0.94$ & 0.017 & & & NA \\
\hline Blood transfusion: yes vs no & 1.07 & $0.66-1.75$ & 0.777 & & & NA \\
\hline CD34: positive vs negative & 5.22 & $1.67-16.3$ & 0.004 & 3.50 & $1.14-10.78$ & 0.029 \\
\hline CK18: positive vs negative & 1.03 & $0.68-1.54$ & 0.903 & & & NA \\
\hline CK19: positive vs negative & 0.82 & $0.42-1.62$ & 0.573 & & & NA \\
\hline HEP-1: positive vs negative & 1.44 & $0.88-2.36$ & 0.150 & & & NA \\
\hline
\end{tabular}

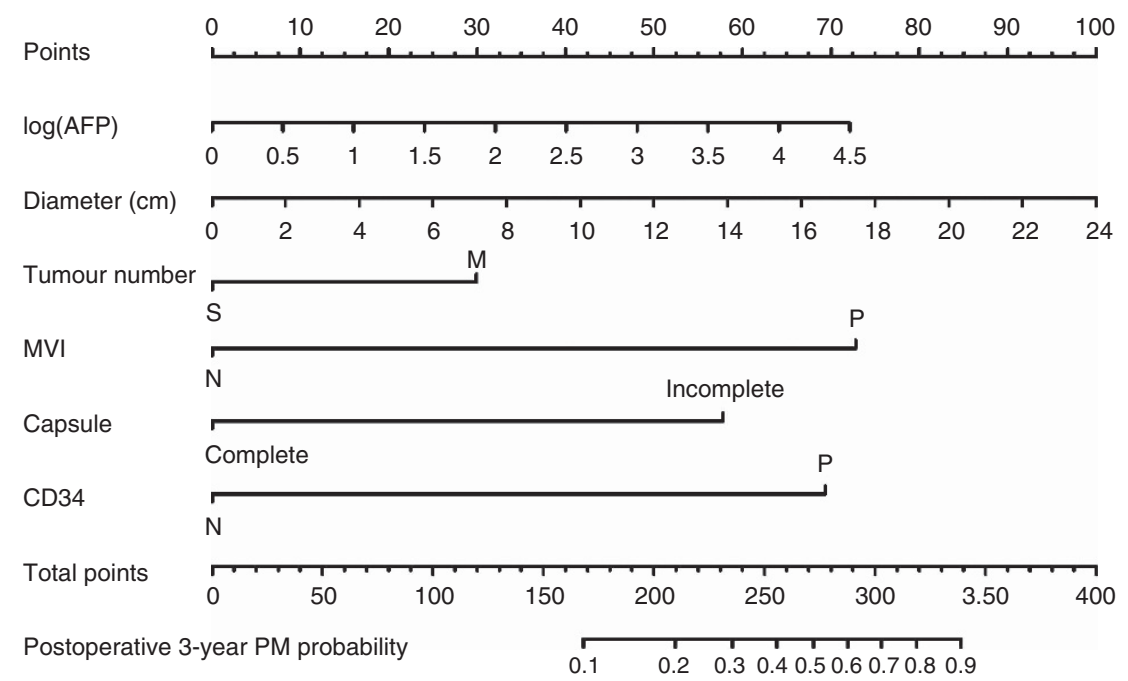

Figure 1. Nomogram for predicting PM of HCC patients following hepatectomy. To calculate the probability of PM, first determine the value for each factor by drawing a vertical line from that factor to the points scale. Then sum up all the individual values and draw a vertical line from the total points scale to the probability at the Probability at the year 3 line to obtain the PM estimates. AFP, preoperative level of serum $\alpha$-fetoprotein; $\mathrm{MVI}$, presence of MVI.

and $86.0 \%$ of the patients had a single tumour nodule at the time of resection (Table 1). There were no significant differences in the characteristics between the two cohorts of patients.
Prognosis of the primary cohort. The median follow-up of the patients was 2.4 years (range: 0.1-9.1 years) and the median time to PM was 1.7 years (range: $0.1-8.9$ years). The postoperative 
1-, 3- and 5-year recurrence and overall survival rates were $43.7 \%$, $68.8 \%$ and $83.7 \%$, and $90.7 \%, 61.2 \%$ and $43.9 \%$, respectively.

At the time of diagnosis of the first recurrence or metastases after hepatic resection, 262 patients had intrahepatic recurrences only; 27 patients had synchronous intrahepatic recurrence and extrapulmonary metastases; 54 patients had extrapulmonary metastases only, including metastases to the peritoneal cavity $(n=19)$, lymph node $(n=15)$, bone $(n=13)$, adrenal gland $(n=5)$, brain $(n=3)$ and other less common sites $(n=3)$. For the 106 patients who presented with PM $(91.5 \%$ within 3 years after surgery) either before or at the same time with recurrences at other sites, they were the subjects in this study.

Construction of the nomogram. Using multivariate analysis, the following six independent variables were selected in the nomogram to predict the 3-year rate of PM (Table 2; Figure 1): preoperative serum AFP level, tumour size, multiple tumour nodules, incomplete tumour encapsulation, presence of microvascular invasion (MVI) and positivity of intratumoral CD34 staining. The model demonstrated good accuracy for predicting a 3-year probability rate of $\mathrm{PM}$, with a $c$-index of 0.75 . Calibration curves revealed good model calibration between the PM estimates from the nomogram and those derived from cumulative incidence function estimates (Figure 2A).

Validation of the nomogram. The median follow-up time of patients was 2.3 years (range: $0.1-8.8$ years), and the median time to PM was 1.5 years (range: $0.1-8.8$ years) in the validation cohort. The recurrence and overall survival rates at 1, 3 and 5 years were $44.2 \%, 73.3 \%$ and $82.2 \%$, and $88.0 \%, 61.0 \%$ and $38.5 \%$, respectively. At the time of diagnosis of the first recurrence or metastasis after hepatic resection, 90 patients had intrahepatic recurrences alone; 7 patients had synchronous intrahepatic recurrence with extrapulmonary metastases; and 20 patients had extrapulmonary metastases only. There were 45 patients who presented with PM before or simultaneously with other tumour recurrences. The nomogram displayed a $c$-index of 0.82 and showed a good calibration curve for predicting the 3-year rate of PM (Figure 2B).

Predictive performance of the nomogram for patients within the Milan criteria. The predictive ability of this nomogram in 428 patients who were within the Milan criteria in the primary and validation cohorts was studied. PM occurred in 46 patients $(10.8 \%)$, which was lower than the rate of PM in patients with more advanced HCC (25.6\%, 105 out of 410$)$. The nomogram displayed a good $c$-index (0.78) and calibration curve (Figure 2C) in predicting postoperative PM in these patients.

Clinical usefulness of nomogram as evaluated by DCA. DCA revealed that the nomogram provided superior net benefit and reduction than that of treating everyone or treating no one, with a probability threshold of $10 \%$ or greater (Figure 3 ).

\section{DISCUSSION}

Pulmonary metastasis following partial hepatectomy for HCC is common. Although progress has been made on the management of $\mathrm{PM}$, there is no method for predicting PM, thus limiting its early detection. In this study, we developed a nomogram with a $c$-index $>0.75$ for such a prediction.

We also tested the role of this nomogram in PM prediction for patients with HCC within the Milan criteria. It is known that this group of patients have a relatively good prognosis after partial hepatectomy (Bolondi et al, 2001), although some still develop early tumour recurrence and metastasis. In our study, $7.0 \%$ of these patients developed PM within 2 years of surgery. Our results suggested that a subset of patients with early HCC who are likely to develop PM after surgery could be identified by this nomogram, which has a $c$-index of 0.78 .

This nomogram included all the important variables of the pathological characteristics, and the serum and tissue tumour biomarkers of HCC, thus making it accurate in the prediction of PM. For the pathological variables, in addition to tumour size and
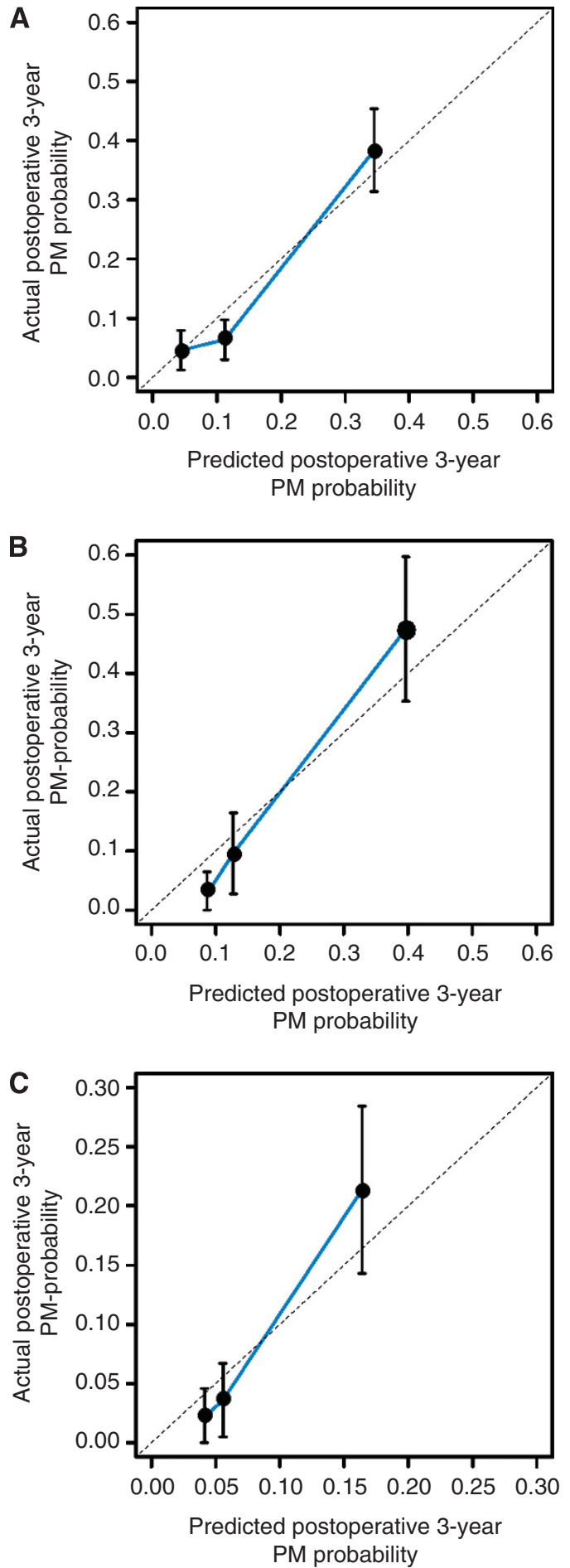

Figure 2. Calibration of the nomogram. The nomogram predicted the probabilities of postoperative PM within 3 years in the primary cohort $(\mathrm{A})$, the validation cohort $(\mathrm{B})$ and in patients who were within the Milan criteria in both the two cohorts, $(\mathbf{C})$ the actual postoperative 3-year PM-probabilities are plotted on the $y$ axis. The predicted postoperative 3-year PM-probabilities are plotted on the $x$ axis. 

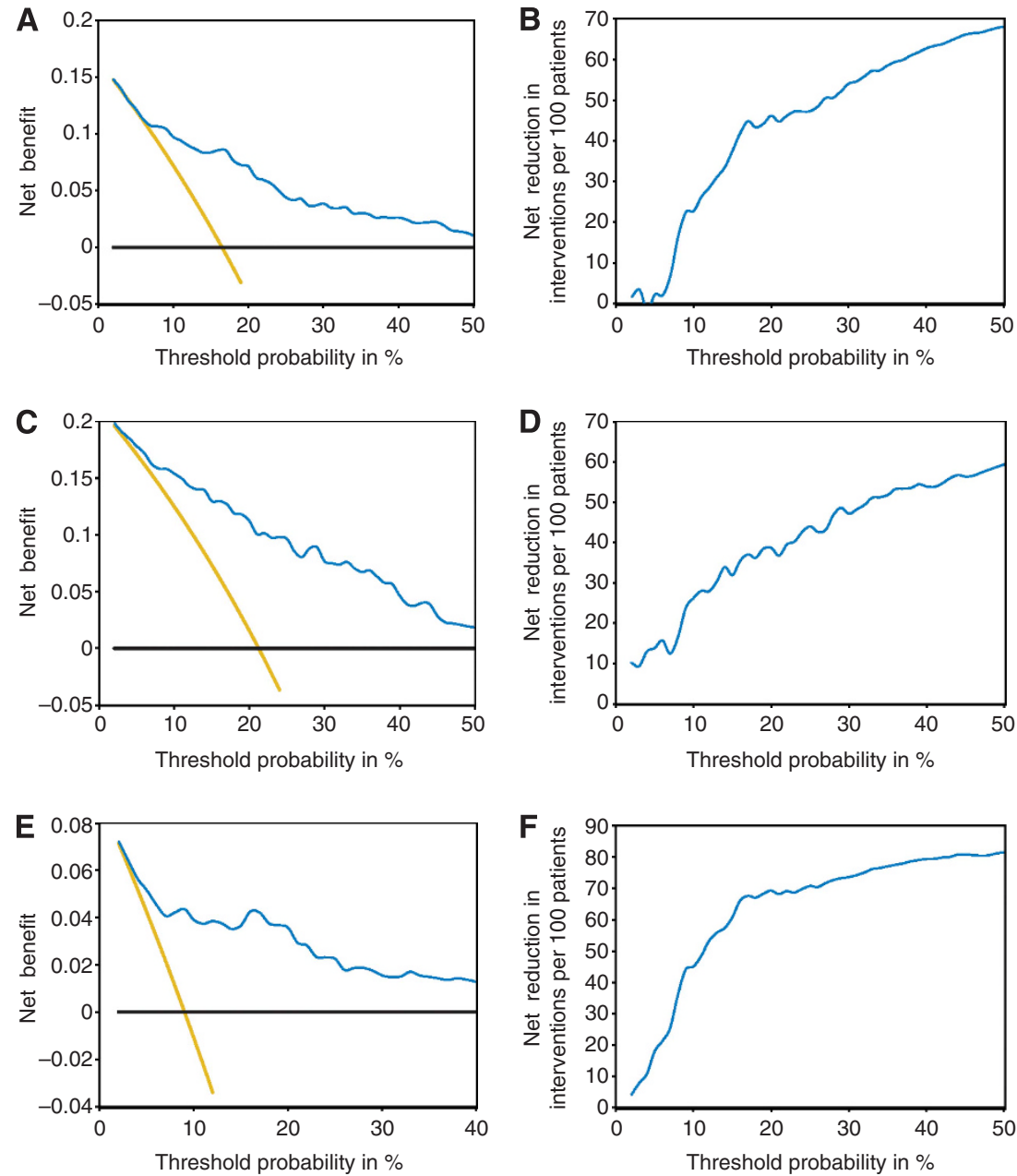

Figure 3. Decision curve analysis of the nomogram. The net benefits ( $y$ axis) as calculated in the primary cohort (A), the validation cohort (C) and in patients who were within the Milan criteria in both the two cohorts, $(E)$ are plotted against the threshold probabilities of PM on the $x$ axis; blue line: nomogram; yellow line: to assume all patients to have PM; horizontal black line: to assume no patients to have PM. Net reduction in interventions per 100 patients at different threshold probabilities of PM are shown in (B), (D) and (F) (the primary cohort, the validation cohort and in patients who were within the Milan criteria).

number, which reflect the stage of disease, MVI and the status of tumour encapsulation were also included. Many published reports have shown the presence of MVI to be correlated with EHM after curative resection for HCC and that MVI is a predictor of poor prognosis (Poon et al, 2000; Sonoyama et al, 2003; Li et al, 2012). Our study also revealed $>60 \%$ of patients with MVI developed PM. Vascular invasion is an indication that the neoplasm has developed to a stage of tumour progression when its tumour cells have developed into a sufficiently evolved phenotype to invade blood vessels and begin the distant metastatic process (Hart, 1997). On the contrary, the influence of tumour encapsulation on distant spread of HCC is less studied, although well-encapsulated tumours are generally known to be associated with a low incidence of direct invasion, microsatellite formation and vascular invasion $(\mathrm{Ng}$ et al, 1992). For unencapsulated or incompletely encapsulated tumours, the cancer cells can directly invade into the surrounding liver parenchyma, causing destruction of the extra-cellular matrix and migration into the circulation (Iguchi et al, 2009). For HCC biomarkers, serum AFP level and intratumoral CD34 were included into the model. Recent studies have showed that a high level of serum AFP to be an independent factor of HCC invasiveness. Also, a high AFP level is closely correlated with both a decrease in immunological function in tumour host and an increase in the invasive ability of HCC cells, thus explaining the relatively poor surgical outcomes (Yamamoto et al, 2007; The Cancer of the Liver Italian Program (CLIP) Investigators, 1998). There have been very few studies on the AFP level of HCC patients with PM after partial hepatectomy. CD34 is an important biomarker of angiogenesis and microvascular density of HCC, and it is closely associated with HCC prognosis (Yang et al, 2010; Ding et al, 2011). A recent study showed that endothelium-coated tumour cell clusters (ECTCs) served as the origin of distant metastasis from HCC, and CD34 was closely involved in ECTC (Ding et al, 2011).

The diagnosis of PM in this study was based on medical imaging and serology, and we cannot completely rule out the possibility of primary pulmonary cancer (PPC) in this series. A previous study has reported the mean incidence of extrahepatic primary malignancy in HCC patients to be $6 \%$; PPC accounted for $17.4 \%$, and less than half of these PPCs occurred after the diagnosis of HCC (Fernández-Ruiz et al, 2009). On the basis of these figures, the calculated number of patients with PPC in our study should be $<4$. Furthermore, in the majority of cases, the diagnosis of PM from HCC was supported mainly by the changes in serum AFP level. In this study, all patients with a preoperative AFP $\geqslant 20 \mathrm{ng} \mathrm{ml}^{-1}(n=112,74.2 \%$ of all patients with $\mathrm{PM})$ presented with re-elevation of the tumour marker when postoperative PM was diagnosed. In addition, the clinical characteristic differences 
between PM and PPC on CT scan can be used in the differentiation (Smith, 1998). It is our belief that the low incidence of PPC and our stringent diagnostic criteria for PM make the results reliable.

The DCA was initially used by Vickers and Elkin as a new analytical technique, incorporating the clinical consequences of a decision, to quantify the clinical usefulness of a prediction model (Vickers and Elkin, 2006). It can therefore determine whether the predictive models are clinically useful or not. In our study, the nomogram showed better net benefit and reduction at a threshold probability of $10 \%$ or greater. This suggested that if the patients were predicted with a probability of PM to be $>10 \%$ by our nomogram, they should be classified to be a high-risk population. Measures to early detect or prevent PM should be instituted. Accordingly, the follow-up of these patients should be more intensive. Thus, regular chest CT scans instead of chest X-ray should be taken (Pomerri et al, 2012) in order to diagnose PM early. The nomogram may also be a useful tool in deciding organ allocation for secondary liver transplantation for HCC patients who have been initially treated with partial hepatectomy. A patient who is predicted to have a high risk of PM by the nomogram may not be an appropriate candidate for cadaveric liver transplantation.

This study has the following limitations: (a) most of our patients had a background of HBV infection (81.1\%) and non-cirrhosis $(67.8 \%)$. Although the proposed nomogram also produced good $c$-indexes $(0.758$ or 0.757$)$ for prediction of PM in cirrhotic or $\mathrm{HBV}$-negative patients, its performance in the patients with other underlying disease remains to be further studied. (b) Although the nomogram was based on competing risk analysis for the probability of postoperative PM, we still cannot conclude that the nomogram is absolutely specific for PM. However, the nomogram is relatively specific for PM because the $c$-indices of the nomogram in predicting PM-free EHM were 0.51 and 0.70 in the primary and validation cohorts, which were significantly lower than those in predicting PM $(0.75$ and $0.82, P<0.01)$.

In conclusion, we have developed a reliable nomogram to predict postoperative PM of HCC. This is a useful tool for the early diagnosis and prevention of PM. The identification of organspecific biomarkers is still a challenge in cancer metastasis (Nguyen et al, 2009). With progress, a model with higher specificity and accuracy than our nomogram may be established in the future.

\section{ACKNOWLEDGEMENTS}

This work was supported by the State Key Project on Infectious Diseases of China (2008ZX10002-025, 2012ZX10002016 to FS), Grant of Shanghai Hospital Development Program (SHDC12010121 to FS) and Natural Science Foundation of Shanghai (12ZR1439700 to JL).

\section{CONFLICT OF INTEREST}

The authors declare no conflict of interest.

\section{REFERENCES}

Baek SJ, Kim SH, Kwak JM, Cho JS, Shin JW, Amar AH, Kim J (2012) Indeterminate pulmonary nodules in rectal cancer: a recommendation for follow-up guidelines. J Surg Oncol 106: 481-485.

Bhattacharjya S, Aggarwal R, Davidson BR (2006) Intensive follow-up after liver resection for colorectal liver metastases: results of combined serial tumour marker estimations and computed tomography of the chest and abdomen - a prospective study. Br J Cancer 95: 21-26.
Bolondi L, Sofia S, Siringo S, Gaiani S, Casali A, Zironi G, Piscaglia F, Gramantieri L, Zanetti M, Sherman M (2001) Surveillance programme of cirrhotic patients for early diagnosis and treatment of hepatocellular carcinoma: a cost effectiveness analysis. Gut 48: 251-259.

Cahlon O, Brennan MF, Jia X, Qin LX, Singer S, Alektiar KM (2012) A postoperative nomogram for local recurrence risk in extremity soft tissue sarcomas after limb-sparing surgery without adjuvant radiation. Ann Surg 255: 343-347.

Cheng AL, Kang YK, Chen Z, Tsao CJ, Qin S, Kim JS, Luo R, Feng J, Ye S, Yang TS, Xu J, Sun Y, Liang H, Liu J, Wang J, Tak WY, Pan H, Burock K, Zou J, Voliotis D, Guan Z (2009) Efficacy and safety of sorafenib in patients in the Asia-Pacific region with advanced hepatocellular carcinoma: a phase III randomised, double-blind, placebo-controlled trial. Lancet Oncol 10: 25-34.

Chua TC, Morris DL (2012) Exploring the role of resection of extrahepatic metastases from hepatocellular carcinoma. Surg Oncol 21: 95-101.

Ding T, Xu J, Zhang Y, Guo RP, Wu WC, Zhang SD, Qian CN, Zheng L (2011) Endothelium-coated tumor clusters are associated with poor prognosis and micrometastasis of hepatocellular carcinoma after resection. Cancer 117: 4878-4889.

Edge SB, Byrd DR, Compton CC, Fritz AG, Greene FL, Trotti A (2009) American Joint Committee on Cancer Staging Manual. 7th edn. Springer: New York.

European association for the study of the liver, European organisation for research and treatment of cancer (2012) EASL-EORTC clinical practice guidelines: management of hepatocellular carcinoma. J Hepatol 56: 908-943.

Feng YX, Wang T, Deng YZ, Yang P, Li JJ, Guan DX, Yao F, Zhu YQ, Qin Y, Wang H, Li N, Wu MC, Wang HY, Wang XF, Cheng SQ, Xie D (2011) Sorafenib suppresses postsurgical recurrence and metastasis of hepatocellular carcinoma in an orthotopic mouse model. Hepatology 53: 483-492.

Ferlay J, Shin HR, Bray F, Forman D, Mathers C, Parkin DM (2010) Estimates of worldwide burden of cancer in 2008: GLOBOCAN 2008. Int J Cancer 127: 2893-2917.

Fernández-Ruiz M, Guerra-Vales JM, Castelbón-Fernández FJ, Llenas-García J, Caurcel-Díaz L, Colina-Ruizdelgado F (2009) Multiple primary malignancies in Spanish patients with hepatocellular carcinoma: analysis of a hospital-based tumor registry. J Gastroenterol Hepatol 24: 1424-1430.

Hart IR (1997) The spread of tumors. In Cellular and Molecular Biology of Cancer, Franks L, Teich N (eds)pp 21-23. Oxford University Press: Oxford.

Hong SS, Kim TK, Sung KB, Kim PN, Ha HK, Kim AY, Lee MG (2003) Extrahepatic spread of hepatocellular carcinoma: a pictorial review. Eur Radiol 13: 874-882.

Iguchi T, Aishima S, Sanefuji K, Fujita N, Sugimachi K, Gion T, Taketomi A, Shirabe K, Maehara Y, Tsuneyoshi M (2009) Both fibrous capsule formation and extracapsular penetration are powerful predictors of poor survival in human hepatocellular carcinoma: a histological assessment of 365 patients in Japan. Ann Surg Oncol 16: 2539-2546.

Kattan MW, Scardino PT (2007) Evidence for the usefulness of nomograms. Nat Clin Pract Urol 4: 638-639.

Kong JH, Lee J, Yi CA, Park SH, Park JO, Park YS, Lim HY, Park KW, Kang WK (2012) Lung metastases in metastatic gastric cancer: pattern of lung metastases and clinical outcome. Gastric Cancer 15: 292-298.

Li J, Yan ZL, Gong RY, Wang YZ, Wan XY, Xue F, Xia Y, Wang K, Liu J, Wu D, Wang HY, Shi LH, Wu MC, Shen F (2012) Independent factors and predictive score for extrahepatic metastasis of hepatocellular carcinoma following curative hepatectomy. Oncologist 17: 963-969.

Llovet JM, Ricci S, Mazzaferro V, Hilgard P, Gane E, Blanc JF, de Oliveira AC, Santoro A, Raoul JL, Forner A, Schwartz M, Porta C, Zeuzem S, Bolondi L, Greten TF, Galle PR, Seitz JF, Borbath I, Häussinger D, Giannaris T, Shan M, Moscovici M, Voliotis D, Bruix J. SHARP Investigators Study Group (2008) Sorafenib in advanced hepatocellular carcinoma. N Engl J Med 359: 378-390.

Mazzaferro V, Regalia E, Doci R, Andreola S, Pulvirenti A, Bozzetti F, Montalto F, Ammatuna M, Morabito A, Gennari L (1996) Liver transplantation for the treatment of small hepatocellular carcinomas in patients with cirrhosis. New Engl J Med 334: 693-699.

$\mathrm{Ng}$ IO, Lai EC, Ng MM, Fan ST (1992) Tumor encapsulation in hepatocellular carcinoma. A pathologic study of 189 cases. Cancer 70: $45-49$. 
Nguyen DX, Bos PD, Massagué J (2009) Metastasis: from dissemination to organ-specific colonization. Nat Rev Cancer 9: 274-284.

Pomerri F, Pucciarelli S, Maretto I, Perrone E, Pintacuda G, Lonardi S, Nitti D, Muzzio PC (2012) Significance of pulmonary nodules in patients with colorectal cancer. Eur Radiol 22: 1680-1686.

Poon RT, Fan ST, Wong J (2000) Risk factors, prevention, and management of postoperative recurrence after resection of hepatocellular carcinoma. Ann Surg 232: 10-24.

Smith EL (1998) Pulmonary metastasis. Semin Oncol Nurs 14: 178-186.

Sonoyama T, Ochai T, Hironaka T, Yamagishi H (2003) Predictors of postoperative diffuse intrahepatic recurrence of hepatocellular carcinoma. Hepatogastroenterology 50: 1078-1084.

Steyerberg EW, Vickers AJ (2008) Decision curve analysis: a discussion. Med Decis Making 28: 146-149.

The Cancer of the Liver Italian Program (CLIP) Investigators (1998) A new prognostic system for hepatocellular carcinoma: a retrospective study of 435 patients. Hepatology 28: 751-755.

Vickers AJ, Elkin EB (2006) Decision curve analysis: a novel method for evaluating prediction models. Med Decis Making 26: 565-574.

Wang K, Liu J, Yan ZL, Li J, Shi LH, Cong WM, Xia Y, Zou QF, Xi T, Shen F, Wang HY, Wu MC (2010) Overexpression of aspartyl-(asparaginyl)$\beta$-hydroxylase in hepatocellular carcinoma is associated with worse surgical outcome. Hepatology 52: 164-173.

Wang Y, Li J, Xia Y, Gong R, Wang K, Yan Z, Wan X, Liu G, Wu D, Shi L, Lau W, Wu M, Shen F (2013) Prognostic nomogram for intrahepatic cholangiocarcinoma after partial hepatectomy. J Clin Oncol 31: 1188-1195.

Yamamoto J, Kosuge T, Saiura A, Sakamoto Y, Shimada K, Sano T, Takayama T, Sugawara Y, Yamaguchi T, Kokudo N, Makuuchi M (2007) Effectiveness of hepatic resection for early-stage hepatocellular carcinoma in cirrhotic patients: subgroup analysis according to Milan Criteria. Jpn J Clin Oncol 37: 287-295.

Yang XR, Xu Y, Yu B, Zhou J, Qiu SJ, Shi GM, Zhang BH, Wu WZ, Shi YH, Wu B, Yang GH, Ji Y, Fan J (2010) High expression levels of putative hepatic stem/progenitor cell biomarkers related to tumour angiogenesis and poor prognosis of hepatocellular carcinoma. Gut 59: 953-962.

Yang Y, Nagano H, Ota H, Morimoto O, Nakamura M, Wada H, Noda T, Damdinsuren B, Marubashi S, Miyamoto A, Takeda Y, Dono K, Umeshita K, Nakamori S, Wakasa K, Sakon M, Monden M (2007) Patterns and clinicopathologic features of extrahepatic recurrence of hepatocellular carcinoma after curative resection. Surgery 141: 196-202.

This work is published under the standard license to publish agreement. After 12 months the work will become freely available and the license terms will switch to a Creative Commons AttributionNonCommercial-Share Alike 3.0 Unported License. 